\title{
Entrevista a Sharan Burrow
}

\author{
27 de enero de 2021
}

Revista Derechos en Acción ISSN 2525-1678/ e-ISSN 2525-1686

Año 6/No 18, Verano 2020-2021 (21 diciembre a 20 marzo), 856-862

DOI: https://doi.org/10.24215/25251678e500

Sharan Burrow es la Secretaria General de la Confederación Sindical Internacional (ITUC) y anterior Presidenta del Consejo australiano de Sindicatos (ACTU) (2000-2010). Es la primera mujer en convertirse Secretaria General del ITUC desde su fundación en 2006, y fue la segunda mujer en convertirse en Presidenta del ACTU. Se graduó como licenciada de la Uni-

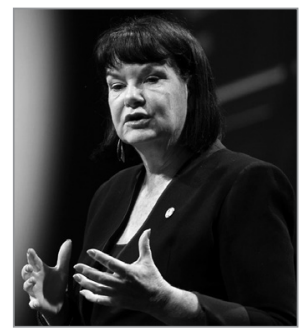
versidad de Nueva Gales del Sur (Australia). Antes de convertirse en Presidenta del ACTU fue también Presidenta de la Unión de Educación australiana (AEU) en 1992. Burrow integra el Consejo de Supervisión de la Fundación Europea para el Clima y es co-presidenta honoraria del Proyecto de Justicia mundial.

- ¿Qué rol cree usted que juegan el FMI y otras IFI en la reducción, de larga data, de la participación del trabajo en el PIB en la mayoría de las economías del mundo?

- La desconfianza de muchos países en desarrollo, de la clase trabajadora y de la sociedad civil hacia el FMI fue aumentando a medida que el mandato institucional se inclinó cada vez más a incorporar el fallido modelo económico del Consenso de Washington o la teoría del goteo. Durante décadas, el FMI y el $\mathrm{BM}$ impulsaron una agenda basada en un fundamentalismo de 
mercado que impuso políticas que perjudicaron a los trabajadores y profundizaron la desigualdad salarial.

Respecto a los salarios, la agenda del FMI explícitamente promovió una estrategia de supresión salarial bajo la pretensión de "impulsar la competitividad" en el sector privado, y pide directamente a los países que reduzcan los salarios en el sector público.

Una investigación del mismo FMI identificó un impacto negativo en la desigualdad por parte de ciertos conjuntos de políticas, por ejemplo: las reformas del mercado laboral, los cambios regulatorios en los mercados de bienes y servicios, la liberalización de la cuenta de capital y las medidas de austeridad, tales como la supresión de los salarios mínimos y la reducción de la protección social. También se demostró que la distribución mejoró allí donde los sindicatos y las prácticas de negociación colectivas son fuertes. Más allá de dicha investigación, salvo pocas excepciones, los programas del FMI y el asesoramiento a nivel país siguen siendo los mismos, a pesar de los niveles históricos de desigualdad que crearon.

- La actual arquitectura financiera internacional, y en especial el FMI, ¿está preparada para enfrentar la crisis pandémica con una mirada progresiva? ¿Qué cambios serían necesarios?

-El liderazgo de Kristalina Georgieva fue alentador por su apoyo al alivio de la deuda, a los derechos especiales de giro y a los swaps de liquidez, y porque reforzó los instrumentos para préstamos de emergencia sin condiciones, además de utilizar el Fondo Fiduciario para Alivio y Contención de Catástrofes para cubrir los propios reembolsos correspondientes a los miembros más pobres. Pero no contó con el apoyo incondicional de las naciones clave. Quizás el resultado de las elecciones estadounidenses y la administración de Biden puedan contribuir a modificar esta dinámica.

Pero esos primeros pasos no alcanzaron ni siquiera a generar la posibilidad de contener la magnitud de la crisis, ni a tener 
impacto alguno en la cantidad de financiamiento que los países necesitan para recuperarse de los embates de la COVID y desarrollar resiliencia.

Para ponerlo en perspectiva, la UNCTAD estimó que los países en desarrollo necesitan 2,5 billones de dólares (es decir, 2500000 millones). El FMI dice que puede prestar hasta 1 billón, dice que ya comprometió 100 mil millones de dólares en financiación, pero en realidad solo desembolsó unos 30 mil millones de dólares en 2020, para repartir entre unos 80 países. Para dar algo de perspectiva, el FMI desembolsó 27 mil millones de dólares en 2019, 36 mil millones de dólares en 2018; de los cuales, en esos dos años, 45 mil millones de dólares fueron solo para Argentina.

A fin de dar una respuesta más progresiva, el FMI debería condonar muchas más deudas y, al menos, extender esa opción a los países de ingresos medios-bajos, así como dar mucho más financiamiento sin condiciones regresivas.

Apoyar una gran emisión de DEG también ayudaría, así como ofrecerles apoyo desvinculado a la deuda a todos los países, y alentar a los países desarrollados que no necesitan ese apoyo a donar su asignación al CCRT (para un mayor alivio de la deuda).

-E1 FMI evitó sistemáticamente comprometerse con políticas de protección laboral, como las normas básicas impulsadas por la OIT. ¿Cuáles son las principales cuestiones de la visión del FMI que obstaculizan el pleno cumplimiento de los derechos laborales?

-El contrato social empezó a romperse seriamente en los años 80 con la hiperglobalización y la pérdida del compromiso tanto con el pleno empleo como con la negociación colectiva y la prosperidad compartida. El predominio de las ganancias de los accionistas intensificó un modelo explotador de cadenas de suministro globales basado en mano de obra de bajos salarios y que tuvo por resultado niveles de desigualdad históricos, que 
han generado desesperación y enojo entre las personas. De hecho, podemos atribuir la pérdida de confianza en los gobiernos y en la democracia misma al alcance de este fracaso.

La visión del FMI de que el "libre mercado" ofrece los mejores resultados supone erróneamente que el incremento salarial debería ser solo un reflejo de la productividad y de la productividad laboral, hasta el punto de que cualquier intervención es una distorsión de los mecanismos del mercado. De esto se desprende un principio operativo que entiende que una postura enfática respecto de las normas laborales podría perjudicar de alguna manera al crecimiento.

Hubo ciertos avances en la manera en que se aborda esta ortodoxia, en el sentido de que el FMI reconoció que a veces los mercados fallan y que algunas intervenciones, como los salarios mínimos, pueden ser útiles; pero se siguen pensando como una excepción más que como la aceptación de que la prosperidad compartida eleva la demanda agregada y el crecimiento inclusivo.

Trágicamente, los modelos del FMI aún asumen que la solución para reducir la informalidad es tener menos derechos laborales (y en general menos regulaciones), cuando en realidad la solución más rápida son el ingreso mínimo vital y la protección social en un mercado laboral regulado basado en derechos.

- ¿Cuáles son las normas laborales buenas y malas que vio adoptar a los Estados para lidiar con la pandemia y la recesión, y cuál es la opinión del FMI respecto de esas reformas legislativas? ¿Tiene el FMI su propio enfoque laboral en tiempos de COVID-19?

- Los peores ataques a los derechos fueron por parte de Estados autoritarios que usaron la pandemia para legislar contra los derechos y libertades de su propio pueblo. India, Indonesia, Filipinas y Brasil, entre otros, son ejemplos del poder de élites corruptas que actúan con brutal desprecio por las personas y, 
en última instancia, por las economías inclusivas y sostenibles. Las instituciones multilaterales no han logrado moderar ese comportamiento en ninguna parte.

-Los mercados laborales ya enfrentaban un desafío producto de un proceso estructural, en el marco del debate que se conoce principalmente como "el futuro del trabajo" (por ejemplo, la automatización, la digitalización, la inteligencia artificial, etc.). ¿La crisis pandémica está funcionando como una oportunidad para afrontar este desafío sin una protección adecuada para los y las trabajadoras? ¿Las IFI juegan algún papel en este proceso durante la crisis?

- La tecnología que le brinde un servicio a la humanidad debe ser bienvenida, pero debemos oponernos al determinismo tecnológico. La COVID-19 aceleró el uso de las tecnologías digitales, pero, siendo que menos del $20 \%$ de los trabajos tienen la posibilidad de desarrollarse remotamente, hoy el panorama es mucho más complejo. Si pudiéramos garantizar que todos los trabajos mediados por Internet contaran con un piso de derechos, salarios decentes y protección contra la explotación, podríamos contar con trabajo decente. Si elimináramos la vigilancia durante el trabajo y garantizáramos la privacidad online, las personas confiarían en la tecnología. Para ello hacen falta regulaciones que quiebren el monopolio de poder de las grandes compañías tecnológicas. Se requieren regulaciones contra los sesgos de los algoritmos implementados y su corrupción. Y luego, el desafío central es invertir en empleos de calidad para maximizar la participación en mercados laborales justos.

—¿Qué piensa del enfoque de género del FMI y de otras instituciones de Bretton Woods para lidiar con la pandemia en el campo de las políticas económicas y sociales (incluyendo el trabajo y las jubilaciones)?

-Las instituciones del FMI y del BM están constantemente hablando sobre igualdad de género y el empoderamiento de las 
mujeres. Producen muchos informes y estrategias de género, pero aún impulsan políticas regresivas que perjudican a las mujeres de manera desproporcionada, por ejemplo: al oponerse a la protección social universal y al salario mínimo vital, los recortes salariales del sector público, las reducciones de las pensiones, los impuestos regresivos (incluido el IVA), la financiación insuficiente del sector de la salud y asistencia, de la educación y más.

El FMI está apoyando gastos sociales adicionales como respuesta a la COVID-19, pero el riesgo sigue siendo que luego se vuelva rápidamente a la austeridad, eliminando los beneficios logrados al retirar las medidas temporales. Necesitamos inversiones que busquen ofrecer beneficios sociales a largo plazo, con un enfoque paciente sobre la deuda y el capital que respalden un nuevo modelo de desarrollo.

- ¿Qué papel tiene el movimiento sindical internacional a la hora de superar la crisis pandémica, la recesión y las desigualdades radicales persistentes?

—En casi todos los países los sindicatos desempeñaron un papel increíble a la hora de hacer que se implementaran políticas de apoyo al empleo y al salario, y a los ingreso para las personas más necesitadas, así como al acceso a la salud.

Nuestra demanda por un Nuevo Contrato Social para la recuperación y la resiliencia tuvo cierto alcance, pero este es el año para incorporar las cinco demandas críticas de los y las trabajadoras en todo el mundo.

Empleo: trabajos respetuosos con el medioambiente

Derechos: la reparación de un mercado laboral quebrado mediante la promesa de un piso de derechos y protecciones para todos los y las trabajadoras, independientemente de los acuerdos sectoriales. Estos se establecieron en la Declaración del Centenario de la OIT, a saber: derechos fundamentales, salud y seguridad ocupacional, salarios mínimos vitales y una jornada máxima de trabajo. 
Protección social universal: con un fondo de protección social global para cerrar la brecha de financiamiento en los países más pobres que no tienen protección social contra los shocks.

Igualdad: igualdad de ingresos, de género y racial

Inclusión: paz, personas y desarrollo

Esta recuperación se debe financiar con impuestos, no con austeridad. Y solo podremos eliminar el poder de monopolio de las corporaciones y la explotación de las personas y el planeta si acabamos con la impunidad empresarial.

Los y las trabajadoras y sus sindicatos lucharán por una reforma del multilateralismo que apoye un futuro justo y sostenible. 